\title{
Effect of Fibroid on Pregnancy and Pregnancy on Fibroid Uterus
} (Original Article)

\author{
Authors \\ Dr Sufia Begum (FCPS) ${ }^{1}$, Dr Mahina Monsur ${ }^{2}$, Dr Ummul Nusrat Zahan (FCPS) ${ }^{3}$ \\ ${ }^{1}$ Asst. Professor of Obstetrics and Gynaecology, Delta Medical College Hospital \\ ${ }^{2}$ Resident Surgeon of Obstetrics and Gynaecology, Delta Medical College Hospital \\ 3Asst. Professor of Obstetrics and Gynaecology, Delta Medical College Hospital
}

\section{ABSTRACT}

Objective: We study the effect of fibroids on women with pregnancy and pregnancy on uterine leiomyoma (fibroids) documented by ultrasonography.

Materials and Methods: Fifty (50) pregnant women diagnosed with leiomyoma during pregnancy were evaluated clinically and sonographycally. The number, size and location of the fibroid were observed with their impact on pregnancy outcome.

Result: Our study population consisted of fifty pregnant women with fibroid. Among them maximum $72.0 \%$ uterine fibroid were found at the age range between 25-35 years, majority (50.0\%) being primi. The rate of spontaneous pregnancy loss in women with fibroid was $28.0 \%$. Again the loss rate was higher in women with multiple fibroids $40.9 \%$. We observed good assoication of uterine fibroid with first trimester bleeding $28.0 \%$, premature delivery $14.0 \%$, premature rupture of membranes (PROM) $20.0 \%$, abruptio placentae $2.0 \%$ and breech presentation $8.0 \%$. The rate of Caesarean delivery was higher $76.0 \%$ in patients with fibroid. The risk of intrauterine growth retardation (IUGR) 18.0 and congenital anomalies of the fetus were also high (6.0\%). Most common effect of Pregnancy on fibroid is degeneration.

Conclusion: Fibroids with pregnancy appear to increase likelihood of complications during pregnancy, labour and delivery.

Key word: Uterine fibroid, Ultrasonogram, effect.

\section{INTRODUCTION}

Approximately $20-40 \%$ of women of reproductive age are known to have uterine myomas beyond3035 years of age ${ }^{1}$. With wide spread use of ultrasonogram, uterine fibroids are more frequently detected during pregnancy. The prevalence of fibroid among pregnant women ranged form $0.1-3.9 \%^{2-6}$. Uterine myomas cause a variety of complications in pregnancy but is has always been assumed that such complications are due to accelerated growth of this neoplasm caused by increased level of estrogen during pregnancy. When fibroid are identified in the first trimester of pregnancy, the risk of pregnancy loss is elevated. Fibroids especially larger ones are reported to be associated with an increased risk of threatened abortion $^{20}$. During the third trimester of pregnancy uterine fibroids are associated with increased complication like preterm labour, abruptio placentae (APH), pelvic pain, premature rupture of membranes (PROM) and breech presentation ${ }^{7}$. We also evaluated whether the number, location 
or size of the fibroids affected the spontaneous pregnancy loss rate. In addition, the rate of Caesarean delivery is higher in women with fibroid and the risk of uterine inertia leading to post partum heamorage $(\mathrm{PPH})$ is elevated ${ }^{8-16}$. It was earlier observed that $7.0 \%$ of pregnant women with fibroid go into preterm labour ${ }^{17}$. The goal of our study is to assess the outcome of pregnancies and changes of fibroids in which fibroid had been documented sonographycally in the first trimester of pregnancy.

\section{MATERIALS AND METHODS}

We conducted a prospective study of women who had undergone first trimester sonography. We included all patients who met the following criteria. Those were singleton pregnancy, fetal hearbeat documented on sonography, uterine fibroids identified on sonography, known mode of conception and sonogram available for review. Cases were included in the study only if information about pregnancy outcome was available.

Data collected and recorded include maternal age, gestational age at the time of sonography and mode of delivery. All sonograms were reviewed to determine the number of fibroids present, their sizes and their locations.

Machine used for ultrasonogram was Real time grey scale scanner sonoline Adara, Siemens and Logic 200 Pro-series GE, Curvilinear 3.5 MHz probes were used for transabdominal USG. The sonographic examinations were performed transabdominally. In cases in which the transabdominal sonogram were insufficient, regarding location, characteristics and size of the fibroid, transvaginal (TVS) sonography was also performed.

Pregnancy outcome was considered live born when a live infant was delivered at or beyond 28 weeks of gestation or as spontancous loss otherwise. Mode of conception was classified as assisted when pregnancy resulted after treatment for infertility.
Measurements of the fibroid were recorded based on our review of sonograms. The location of a fibroid was classified as submucosal if the part of the fibroid bordered on or protruded into the endometrium, intramural if the fibroid was within the wall of the uterus surrounded by myometrium and subserosal if the fibroid extended to the serosal surface of the uterus. We also assessed the pregnancy loss rates based on the number of fibroid present, size of the largest fibroid and the location of the largest fibroid.

\section{RESULT}

Our study group consists of fifty pregnant women in whom fibroids were documented sonographycally in the first trimester. Fetal cardiac activity was also documented in the first trimester in all cases. The mean maternal age was 27.4 \pm 6.7 years with fibroid. Among the fifty patients with fibroid, $18.0 \%$ of pregnancies resulted from assisted conception. The rate of spontaneous pregnancy loss was $28.0 \%$. Pregnancy outcome was significantly worse in patients with multiple fibroids than in patients with a single fibroid (Table 2), the pregnancy loss rate was $40.9 \%$ in women with multiple fibroids versus $17.9 \%$ in women with single fibroids. Pregnancy loss rates correlate with the size of the largest fibroid (Table 3). The fibroid was classified as Subserosal in 15 patients. Interamural 35 patients and no patients found with Submucosal fibroid. In our study, largest fibroid $(24 \times 24) \mathrm{cm})$ Intramural variety occupying whole length of body including cervix, showed congenital anomalies of the foetus i.e. dolicocephaly.

Many complications were also noted during second and third trimester of pregnancy such as premature rupture of membrane (PROM) in $20.0 \%$ cases, Premature delivery in $14.0 \%$ cases, Abruptio placentae in $2.0 \%$ cases, Placenta previa in $4.0 \%$ cases, less liquor (Oligohydramnios) in $10.0 \%$ cases, breech presentation in $8.0 \%$ cases, preeclampsia in $4.0 \%$ cases and post partum haemorrhage in $16.0 \%$ cases. Among 50 cases 
most of the patients $76 \%$ needed Caesarean section i.e. 38 cases, whereas 12 cases delivered normally (Table 6). In our study intrauterine growth retardation (IUGR) was found in $18.0 \%$ cases, intrauterine death (IUD) $8.0 \%$ cases, congenital anomalies of fetus in $6.0 \%$ cases.

Table 1: General Consideration and Medical Status (N=50)

\begin{tabular}{|l|l|l|}
\hline & No of patients & Percentage \\
\hline Age (year) & & \\
\hline$<25$ & 10 & 20.0 \\
\hline $25-35$ & 4 & 72.0 \\
\hline$>35$ & & 8.0 \\
\hline Marital status & 50 & \\
\hline Married & & 100.0 \\
\hline Number of pregnancies & 25 & \\
\hline 1 & 13 & 50.0 \\
\hline 2 & 12 & 26.0 \\
\hline$\geq 3$ & & 24.0 \\
\hline Maternal medical status & & \\
\hline Diabetes & & \\
\hline Established & 1 & 2.0 \\
\hline Gestational & 3 & 6.0 \\
\hline Hypertension & 2 & 4.0 \\
\hline Anemia & 6 & 12.0 \\
\hline
\end{tabular}

Table 2: Effect on pregnancy based on number of fibroid $(\mathrm{N}=50)$

\begin{tabular}{|l|l|l|l|}
\hline Parameters & $\begin{array}{c}\text { No of patients } \\
\mathrm{n}=50\end{array}$ & $\begin{array}{c}\text { Live born rate } \\
\mathrm{n}(\%)\end{array}$ & $\begin{array}{c}\text { Abortion } \\
\mathrm{n}(\%)\end{array}$ \\
\hline Single fibroid & 28 & $23(78.6)$ & $5(17.9)$ \\
\hline Multiple fibroid & 22 & $13(59.1)$ & $9(40.9)$ \\
\hline 2 & 15 & $10(66.7)$ & $5(33.3)$ \\
\hline 3 & 4 & $2(50.0)$ & $2(50.0)$ \\
\hline$\geq 4$ & 3 & $1(33.3)$ & $2(66.7)$ \\
\hline
\end{tabular}

Single fibroid was found in $28(56.0 \%)$ cases, out in 22(44.0) cases, out of which $13(59.1 \%)$ was of which 22 (78.6) was live born and rest 5 live born and rest 9 (40.9\%) was aborted. (17.9\%) was aborted. Multiple fibroid was found

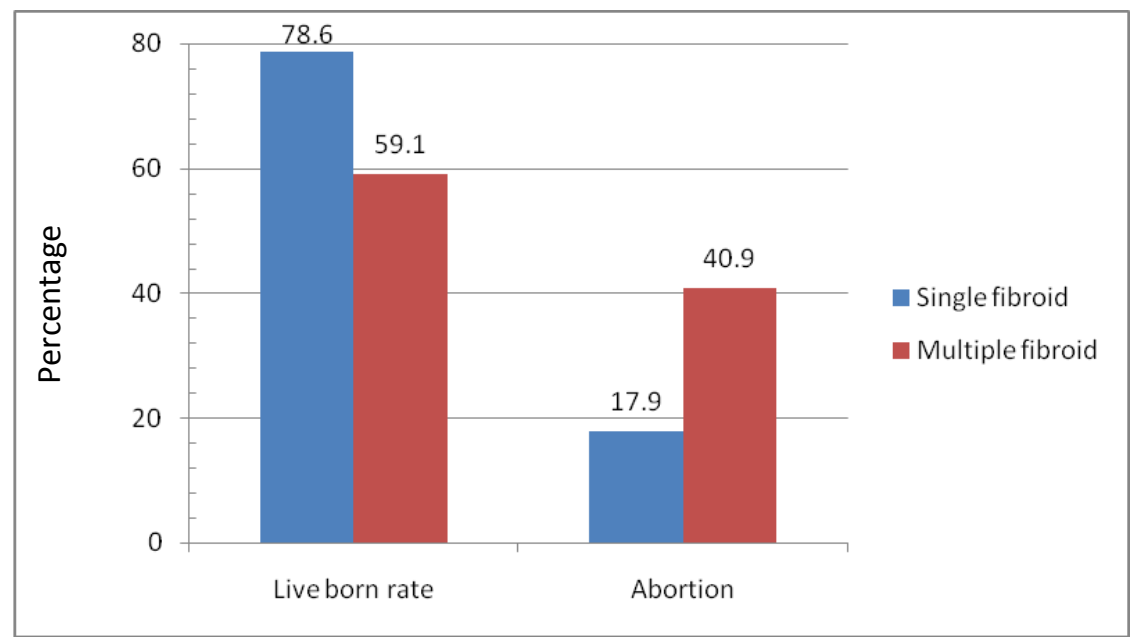

Fig 1: Bar diagram showing outcome of pregnancy with types of fibroids. 
Table 3: Effect on Pregnancy based on size of fibroid (N=50)

\begin{tabular}{|l|l|l|l|}
\hline Parameters & $\begin{array}{c}\text { No of patients } \\
\mathrm{n}=50\end{array}$ & $\begin{array}{c}\text { Live born rate } \\
\mathrm{n}(\%)\end{array}$ & Abortion $\mathrm{n}(\%)$ \\
\hline Size of fibroids & & & \\
\hline$>2 \mathrm{~cm}$ & 3 & $2(66.7)$ & $1(33.3)$ \\
\hline $2-6 \mathrm{~cm}$ & 15 & $12(80.0)$ & $3(20.0)$ \\
\hline $6-10 \mathrm{~cm}$ & 25 & $18(72.0)$ & $7(28.0)$ \\
\hline $10-20 \mathrm{~cm}$ & 7 & $4(57.1)$ & $3(42.9)$ \\
\hline
\end{tabular}

Among the fifty patients, half of them had fibroid cases, out of which $4(57.1 \%)$ was live born and size of $6-10 \mathrm{~cm}$, out of which $18(72.0 \%)$ was live born and $7(28.0 \%)$ was aborted. Size of largest fibroid $10-20 \mathrm{~cm}$ was found in $7(14.0)$ rest 3(42.9\%) was aborted. Abortion case was higher in size of the largest fibroid $10-20 \mathrm{~cm}$.

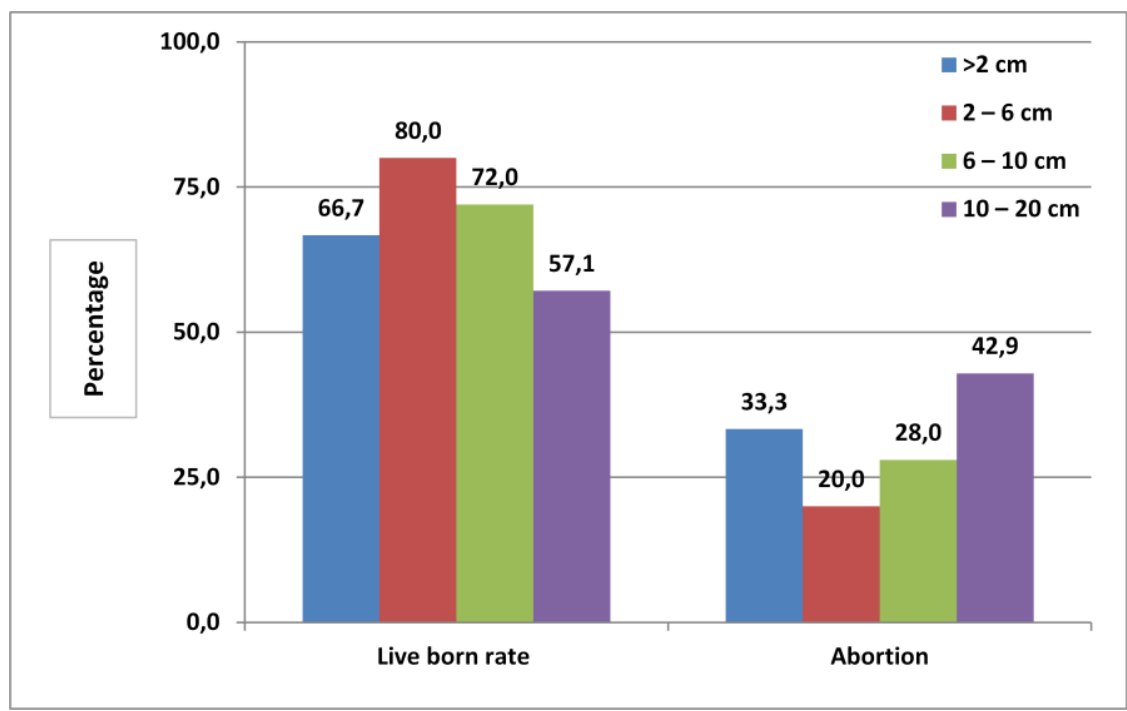

Fig 2: Bar diagram showing Effect on pregnancy with size of fibroids.

Table 4: Effect on Pregnancy based on site of fibroid ( $\mathrm{N}=50$ )

\begin{tabular}{|l|l|l|l|}
\hline Parameters & No of patients $\mathrm{n}=50$ & $\begin{array}{c}\text { Live born rate } \\
\mathrm{n}(\%)\end{array}$ & $\begin{array}{c}\text { Abortion } \\
\mathrm{n}(\%)\end{array}$ \\
\hline Site of fibroids & & & \\
\hline Fundus of uterus & 4 & $3(66.7)$ & $1(25.0)$ \\
\hline Body of uterus & 40 & $30(80.0)$ & $10(20.0)$ \\
\hline Ant wall & 30 & $23(72.0)$ & $7(23.3)$ \\
\hline Post wall & 10 & $8(57.1)$ & $2(20.0)$ \\
\hline Both Ant and Post & 3 & $2(66.7)$ & $1(33.3)$ \\
\hline Lower segment & 3 & $2(66.7)$ & $1(33.3)$ \\
\hline
\end{tabular}

Regarding the site (of uterus) it was observed that $4(8.0 \%)$ cases were found in fundus of uterus, $40(80.0 \%)$ in body of uterus and $3(6.0 \%)$ in lower segment. The rate of abortion related to site of fibroid is shown in table ${ }^{4}$. 


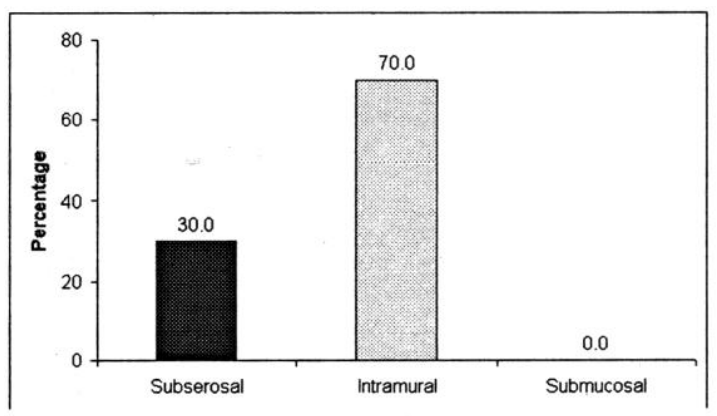

Fig 3: Bar diagram showing fibroid classification of the study patients.

Table 5: Uterine Leiomyomas Complicate pregnancy and labour $(\mathrm{N}=50)$

\begin{tabular}{|l|l|l|}
\hline Labor complications & No of patients & Percentage \\
\hline First-trimester bleeding & 14 & 28.0 \\
\hline Abortion & 12 & 24.0 \\
\hline Placenta previa & 2 & 4.0 \\
\hline Abruption placentae & 1 & 2.0 \\
\hline Oligohydramnios & 5 & 10.0 \\
\hline Preeclampsia & 2 & 4.0 \\
\hline Premature rupture of membrane & 10 & 20.0 \\
\hline Malpresentation (breech) & 4 & 8.0 \\
\hline Premature delivery & 7 & 14.0 \\
\hline Post partum haemorhage & 8 & 16.0 \\
\hline
\end{tabular}

Among the fifty patients with fibroid, commonest complications were first-trimester bleeding, partum haemorhage and premature delivery. Other complications are shown in table ${ }^{5}$ abortion, premature rupture of membrane, post

Table 6: Leiomyomas affect mode of delivery $(\mathrm{N}=50)$

\begin{tabular}{|l|l|l|}
\hline Mode of delivery & No of patients & Percentage \\
\hline Cesarean delivery & 38 & 76.0 \\
\hline Normal vaginal delivery & 12 & 24.0 \\
\hline
\end{tabular}

Cesaream delivery was in $38(76.0 \%)$ and normal vaginal delivery was in $12(24.0 \%)$ cases.

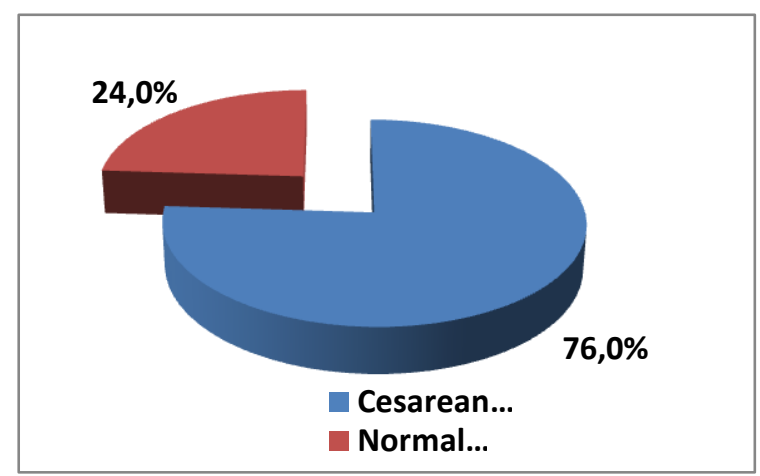

Fig 4: Pie diagram showing mode of delivery of a women pregnancy with fibroid. 
Table 7: Associations between uterine fibroid and fetal outcome $(\mathrm{N}=50)$

\begin{tabular}{|l|c|c|}
\hline Fibroid and fetal out come & No of patients & Percentage \\
\hline Intrauterine growth retardation (IUGR) & 9 & 18.0 \\
\hline Intrauterine death (IUD) & 4 & 8.0 \\
\hline Congenital anomalies a. b.c. & 3 & 6.0 \\
\hline
\end{tabular}

a. Anencephaly b. Dolicocephaly c. Talepes

Intrauterine growth retardation (IUGR) was found in 9(18.0\%) cases, intrauterine death (IUD) in 4(8.0\%) and congenital anomalies in $3(6.0 \%)$ cases.

Effect of PG on Fibroid (N=50)

Table 8: Effect on Fibroid (N=50)

\begin{tabular}{|l|c|c|}
\hline Pregnancy affected Fibroid & No of patients & Percentage \\
\hline Increases the size of Leiomyoma & 50 & $100 \%$ \\
\hline Degeneration of Leiomyoma & 11 & $22 \%$ \\
\hline Infection of Leiomyoma & 3 & $6 \%$ \\
\hline
\end{tabular}

\section{DISCUSSION}

Pregnancies in women with uterine fibroid are at increased risk for pregnancy loss i.e. abortion in first trimester $^{18}$. Our study confirms that the spontaneous pregnancy loss rates are higher in women with fibroid documented during the first trimester. Study conducted by Benson et al. and Rasati et al. also showed the spontaneous pregnancy loss rates are higher in women with fibroid $^{19,20}$. We also found that the spontaneous pregnancy loss rate is high in women with multiple fibroids. Our result also resembles with the study conducted by Benson et al. ${ }^{18}$. Furthermore this study quantified the risk to the pregnancy in relation to number of fibroids, assessed the risk of pregnancy loss in relation to number of fibroids, size of fibroid and location of fibroids (Table 2, $3 \& 4$ ).

At least two retrospective studies suggest that the location of the myomas is important ${ }^{21}$. Those located adjacent to placental site were associated with an increased risk of bleeding, abruption and premature rupture of membrances ${ }^{22,23}$. It is often suggested that the high level of sex steroid associated with pregnancy commonly causes growth of uterine myomas with increased symptoms. However, one prospective study shows that growth is usually seen only in the first trimester and many uterine myomas particularly larger ones often get smaller late is pregnancy ${ }^{24}$.
Study conducted by Rice et al. and Davis et al. ${ }^{3}$ suggested that the size and location of the uterine fibroid might predict the magnitude of the risk ${ }^{2,7}$. In our study among the fifty cases we got same complication during $3^{\text {rd }}$ trimester of pregnancy such as premature delivery in 7 cases $14.0 \%$, breech presentation in 4 cases $8.0 \%$, premature rupture of membranes (PROM) 10 cases $20.0 \%$, oligohydramnios in 5 cases $10.0 \%$, low lying placenta 2 cases 4.0 , and abruptio placenta one case $2.0 \%$. Several studies that addressed breech presentation among women with uterine leiomyomas had significant positive association ${ }^{2}$, 7. Our finding of increased PROM and abruptio placentae among women with uterine myoma is consistent with other study ${ }^{3}$.

Study conducted by Katz et al. and Vergani et al. found that cesarean delivery in women with uterine fibroids in $34.0 \%$ and in $23.4 \%$ cases respectively, which almost resemble with our study 4 , 9. In our study 38 cases $(76 \%)$ were delivered by caesarian section and only 12 cases (24\%) delivered normally (NVD).

The proportion of women who had cesarean section was higher among women with uterine leiomyoma compared with women without them $^{25}$. Infant of women with uterine leiomyoma were of low birth weight. In our study birth weight ranges from $2.5 \mathrm{~kg}$ to $3.0 \mathrm{~kg}$. We found 9 
cases $(18.0 \%)$ of infant with intrauterine growth retardation (IUGR).

Death of foetus (IUD) was also reported among 4 women. Three (3) cases $6.0 \%$ showed congenital anomalies like Anencephaly, Dolicocephaly \& Telepes. Whether there is any relation of fibroid and congenital anomalies of fetus was not well established.

The biological basis for the association between pregnancy, labour or delivery complications and uterine leiomyomas is unclear $^{3}$. Some research suggested that leiomyomas that are behind the placente or in the lower uterine segment increase the likelihood of delivery complications 1, 6, 7 . Uterine myomas also decrease uterine dispensability and cause mechanical obstructions that restrict space and limit fetal movement uterine fibroids also interfere with uterine contractions.

In this study, we observed that uterine leiomyoma was strongly related to first trimester bleeding, abortion, premature rupture of membrane, premature delivery and low birth weight and degenerations. These results are consistent with hypotheses that uterine leiomyomas might interfere with normal labour and delivery by mechanical process. Future investigation should focus on how to minimize risk among pregnant women with uterine leiomyoma.

In summary, uterine fibroids are associated with an elevated risk of spontaneous pregnancy loss after a fetal heartbeat has been visualized by sonography in first trimester. The loss rate is higher in women with multiple fibroids and largest size of fibroid.

\section{REFERENCES}

1. Gomple C. Pathology in Gynecology and obstetrics $2^{\text {nd }}$ ed. Philadelphia, Lippincott 1977:184.

2. Rice JP, Kay HH, Mahony BS. The clinical significance of uterine leiomyomas in pregnancy. Am J Obstet Gynecol 1989; 160:1212-6.
3. Exacoustos $\mathrm{C}$, rosati P. Ultrasound diagnosis of uterine myomas and complications in pregnancy. Obstet Gynecol 1993; 82:97-101.

4. Katz VL, Dotters DJ, Droegemueller W. Complications of uterine myomas and complications in pregnancy. Obstet Gynecol 1989; 73:593-6.

5. Burton CA, Grimes DA, March CM. Surgical management of leiomyomata during pregnancy. Obstet Gynecol 1989: 74:593-6.

6. Hasan F, Arumugam K, Sivanesaratnam V. Uterine leiomyomata in pregnancy. Int J Gynaecol Obstet 1991; 34-45-8.

7. Davis JL, Ray-Mazumder S, Hobel CJ, Baley K, Sassoon D. Uterine leiomyomas in pregnancy: A prospective study. Obstet Gynecol 1990; 75:41-4.

8. Rosati P, Exacoustos C, Mancuso S. Longitudinal evaluation of uterine myoma growth during pregnancy. J Ultrasound Med 1992; 11:511.

9. Vergani P, Ghidini A, Strobelt N, et al. Do uterine leiomyomas influence pregnancy outcome? Am J Perinatol 1994; 11:356.

10. Rice JP, Kay HH, Mahoney BS. The Clinical significance of uterine leiomyomas in pregnancy. Am $\mathbf{J}$ obstet Gynecol 1989; 160:1212.

11. Katz VL. Dotters DJ, Droegemueller W. Complications of uterine leiomyomas in pregnancy. Obstet Gynecol 1989; 73:593.

12. Muram D, Gillieson M, Walters JH. Myomas of the uterus in pregnancy: ultrasonographic follow-up. Am J Obstet Gynecol 1980; 138:16.

13. Davis JL, Ray-Mazumder S, Hobel CJ, et al. Uterine leiomyoms in pregnancy: a prospective study. Obstet Gynecol 1991; $75: 41$.

14. Phelan JP. Myomas and pregnancy, Obstet Gynecol Clin North Am 1995; 22:801. 
15. Lev-Toaff AS Coleman BG, Arger Ph, et al. Leiomyomas in pregnancy: sonographic study. Radiology 1987; 164:375.

16. Exacoustos C, Rosati P, Ultrasound diagnosis of uterine myomas and complications in pregnancy. Obstet Gynecol 1993; 82:97.

17. Ghristine M, David A: uterine' Leiomyomas in the infertile patients, Radiology, 1988, 167:627-630.

18. Carol B. Benson, Jeanne S. Chow, Wendy Chang-Lee, Jiseph A, Hill III, Peter M. Doubilet, Outcome a pregnancies in women with uterine lieomyomas Identified by Sonography in the First Trisesta. 2001; 29:45-9.

19. Benson CB, Doubilet PM, Cooney MJ, Early singleton pregnancy outcome: effects of maternal age and mode of conception. Radiology 1997:203:399.

20. Rosati P. Bellati U, Exacoustos C et al. Uterine myoma in pregnancy: ultrasound study. Int J Gynaecol Obstet 1989; 28:109.

21. American society for Reproductive Medicine, Bironighans, Alaboma. Fertility and sterility. Vol. 82, SUPPL. $1^{\text {st }}$ September 2004.

22. Rice JP, Kay HH, Mahony BS. The clinical significance of uterine leiomyomas in pregnancy. Am J Obstet Gynecol 1989; 160:1212-6.

23. Muram D, Gillieson M, Walters JH. Myomas of the uterus in pregnancy: ultrasonographic follow-up. Am J Obstet Gynecol 1980; 138:16-9.

24. Lev-Toaff AS, Coleman BG, Arger PH, Mintz MC, Arenson RL, Toaff Me. Leiomyomas in pregnancy: sonographic study. Radiology 1987;164:375-80.

25. Gloria D, Coronado, LYNW, M. MARSHALL, Sed, AND Stephen M, Schwartz, Complications of pregnancy Labour and Delivery with literal,
Leiomyomas: A population Based study 2002; 95:43-45. 